\title{
DIRECTIONAL 1900 MHZ SQUARE PATCH RING SLOT MICROSTRIP ANTENNA FOR WCDMA
}

\author{
Irfan Mujahidin
}

\begin{abstract}
Telecommunications systems especially WCDMA networks, require an antenna to convert electromagnetic energy in the air into electrical energy will be processed into the information signal. WCDMA (Wideband Code-Division Multiple Access) network works at a frequency of $1900 \mathrm{MHz}$ with a complicated configuration antenna and has high-cost components. Directional 1900 MHz Square Patch Ring Slot Microstrip Antenna for WCDMA has been proposed. This is a novel technique in telecommunication configuration to make directional antenna use more proper and efficient component by using low cost and easy to find material at $1900 \mathrm{MHz}$ frequency. This compact configuration consists of a single rectangular patch, a substrate, a ground plan and ring slot on the ground plane. This antenna produces an accurate frequency at $1900 \mathrm{MHz}$ with the value of $-\mathbf{1 5 . 1 9}$ $\mathrm{dB}$ and gains $6.78 \mathrm{dBi}$ at. The overall size of the proposed antenna is $55.7 \mathrm{~mm}$ times $49.2 \mathrm{~mm}$ with FR4 (Phenolic White Paper) with a dielectric constant value is 4.4.
\end{abstract}

Index Terms-Microstrip Antenna, Square Patch Ring Slot, Antenna For WCDMA

\section{INTRODUCTION}

A CTUALLY, in the recent time, there has been an intensity increasse in interest of microstrip antennas due to the development of communication technologies especially WCDMA electromagnetic component. Various compact antenna for WCDMA[1].

The configuration of WCDA electromagnetic system requires a compact and low-cost component. In some practices, we use complex antennas configuration and use different types of electrical circuits to get the true frequency, usually use a complex filter. This requires not low-cost and not easy to find material because this requires high-frequency antenna need the material with the lowest loss[2]-[6]. In addition, integrating the antenna has a consequence in complicated fabrication to get true frequency so requires a lot of electric circuits that expensive[7]. The method using the various antenna and line feed circuits more compact than the general antenna. furthermore, the enforcement and empirical, this model is very easy to duplicate, fabricate and can be harness. With a small size and has, a high-frequency antenna is also capable of producing high gain. Even the

Irfan Mujahidin are with the Electrical Engineering Departement of Universitas Merdeka Malang, Malang, Indonesia (email irfanmj7@gmail.com). proposed antenna is capable of providing the directional antenna[8]-[12].

In this letter, a compact antenna consisting of a $1900 \mathrm{MHz}$ with the single patch, single transmission line, and ring slot has been adopted to obtain capable to produce high gain and directional radiation pattern[13]. This study provides a simple and effective method for designing WCDMA antenna without a complex fabrication process and using low-cost materials at high frequency[14].

\section{RESEARCH METHODS}

Fig. 1 and Table 1 shows the geometry of the proposed structure $1900 \mathrm{MHz}$ Antenna. In this Fig., single transmission lines $\lambda / 4$ has been constructed using an FR4 substrate with a thickness of $0.8 \mathrm{~mm}$.
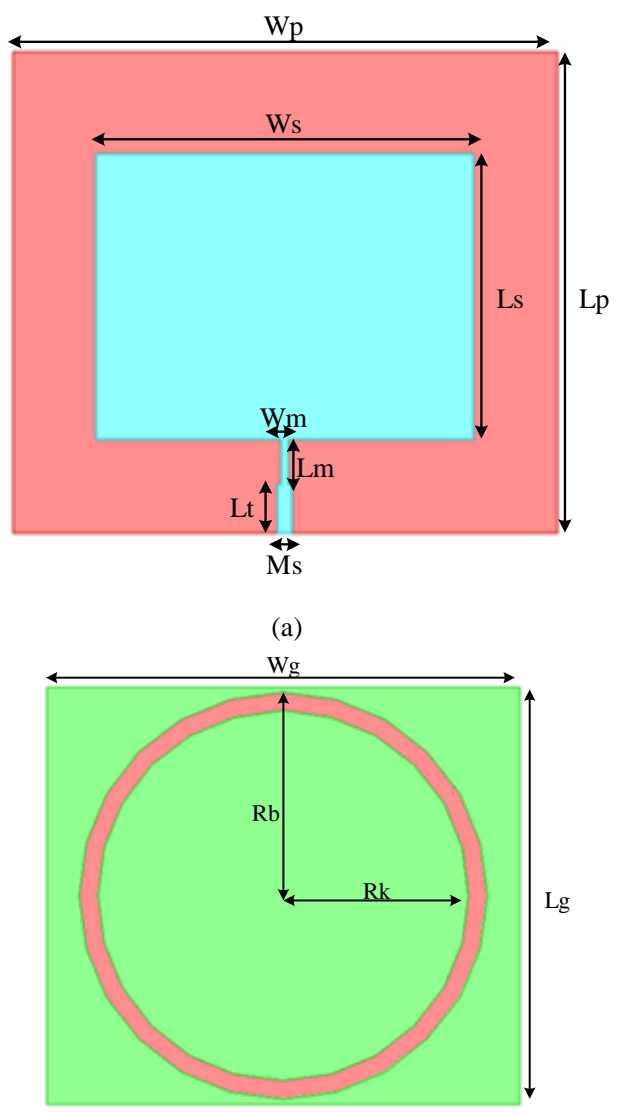

(b)

Fig 1. Structure of Directional $1900 \mathrm{MHz}$ Square Patch Ring Slot Microstrip Antena

(a) Front, (b) Rear 
TABLE I

UNITS FOR MAGNETIC PROPERTIES

\begin{tabular}{cc}
\hline \hline Symbol & $\begin{array}{c}\text { Dimensions } \\
(\mathrm{mm})\end{array}$ \\
\hline $\mathrm{Wp}$ & 55.48 \\
Lp & 49.94 \\
$W s$ & 38.42 \\
$\mathrm{Ls}$ & 29.50 \\
$W m$ & 0.78 \\
$L m$ & 4.50 \\
$L t$ & 5.00 \\
$M s$ & 1.50 \\
$W g$ & 55.48 \\
$L g$ & 49.94 \\
$R b$ & 24 \\
$R k$ & 21.50 \\
\hline \hline
\end{tabular}

In this research, the rectangular shape patch used the connection to the transmission line, which is the radiating element width and length of dimensions can be obtained through the equation [15][3]:

$$
\frac{\Delta L_{g}}{h}=0.421 \frac{\left(\epsilon_{\text {reff }}+0.3\right)\left(\frac{W s}{h}+0.264\right)}{\left(\epsilon_{\text {reff }}+0.258\right)\left(\frac{W}{h}+0.8\right)}
$$

Where $L p$ is the length of the radiation element, $W s$ is the width of the radiation element, $h$ is the thickness of the substrate, and Ereff is the effective dielectric constant of the substrate. Single square patch and ring slot antenna design is done mathematically based on the material and references. Results of the draft then simulated using the design software to determine the parameters of the Single square patch and ring slot antenna[16]-[18].

\section{RESUlt AND ANALIYSIS}

In figure 2 is $\mathrm{s}$ parameter result of the Directional 1900 MHz Square Patch Ring Slot Microstrip Antenna.

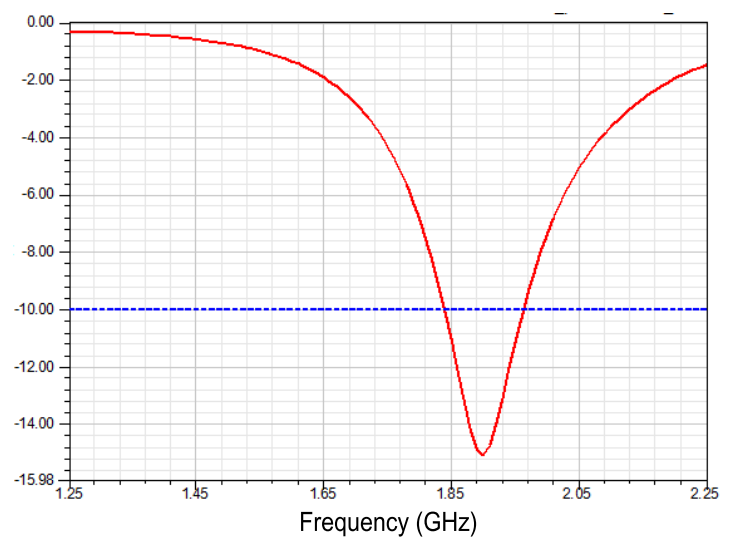

Fig. 2. S Parameter Antenna
$\mathrm{S}$ parameter value of the antenna has good agreement return loss values of $-15.66 \mathrm{~dB}$ on $1900 \mathrm{MHz}$ that is true frequency and over all the frequency target under $-10 \mathrm{~dB}$ so that is have the band of $1840 \mathrm{MHz}-1960 \mathrm{MHz}$. To describe the graphics properties of far-field antenna radiation pattern as a function of spatial coordinates (three dimensions) [19]. It is necessary to know the square patch ring slot microstrip antenna radiation pattern. The following Figure 3 is the antenna radiation pattern:

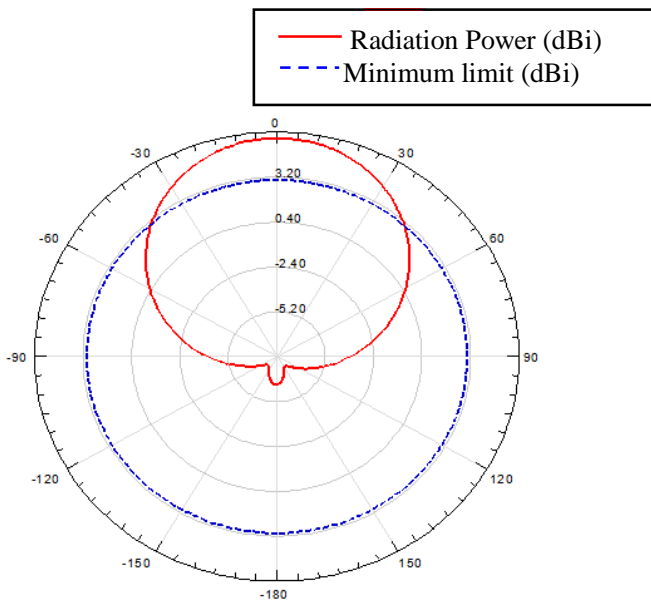

(a)

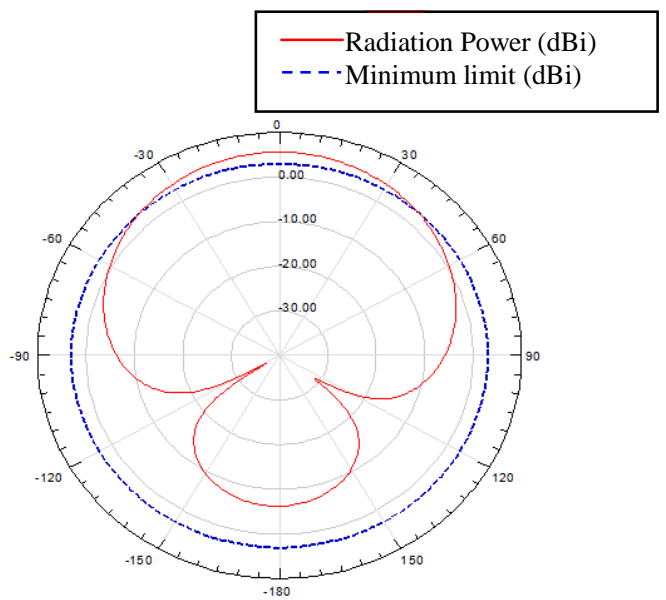

(b)

Fig 3. (a) Theta angles of The radiation pattern, and (b) Phi angles of The radiation pattern

The radiation pattern of the results has the good agreement magnitude of the shape and the value still the above maximum limit. From the shape of the radiation pattern has a main lobe of the biggest area and has a very small side area lobe and back lobe, it can be concluded that the antenna radiation pattern is a directional radiation pattern[20]-[22]. To know the strengthening power in a certain direction to the reinforcement of the antenna reference power hence need to know antenna gain value[23]. Following gain value: 


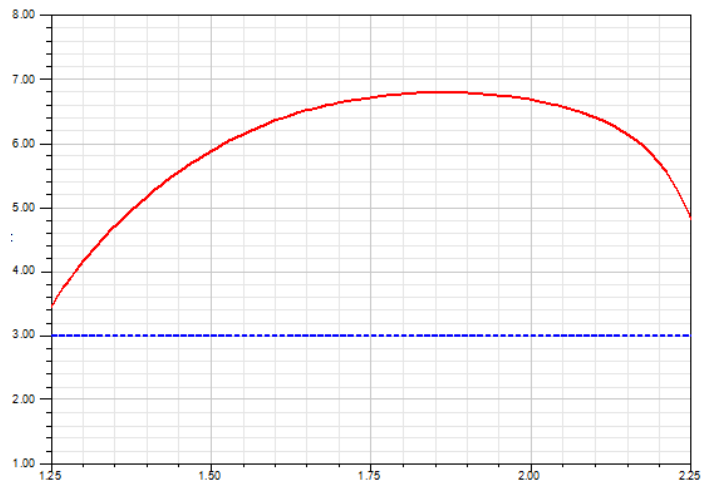

Fig 4. The gain value microstrip antenna

From Figure 4, it is shown that the gain of the antenna has a value of $6.78 \mathrm{dBi}$. this shows that high antenna gain for microstrip antenna with the frequency of $1900 \mathrm{MHz}$.

\section{CONCLUSION}

In this letter, a compact prototype antenna, easy to imitate and low-cost material that has FR4 material with $\varepsilon r=4.4$. This antenna has single transmission line $\lambda / 4$ with the working frequency of resonator that is 1900 $\mathrm{MHz}$. This antenna is a directional antenna with a high gain of $6.78 \mathrm{dBi}$, directional radiation pattern and linear polarization. $\mathrm{S}$ output parameters under $10 \mathrm{~dB}$ that is has a value of $-15.66 \mathrm{~dB}$ and have the band of 1840 $\mathrm{MHz}-1960 \mathrm{MHz}$. overall result and analysis antenna is a good agreement for WCDMA application.

\section{REFERENCES}

[1] Thierry, T \& dan Valerie, V. 2012. A 900Mhz RF Energy Harvesting Module. "New Circuit and Systems Conference (NEWCAS). IEEE 10th International Meeting, Canada". hal00827697.

[2] Visser. Hubregt J. 2001. Ambient RF Energy Scavening: GSM and WLAN Power Density Measurements. Proceedings of the 38th European Microwave Converence p.721-724.

[3] Balanis, C.A. 1982. Antenna Theory: Analysis and Design, $2^{\text {nd }}$ Edition. John Wiley and Sons, Inc.

[4] Kavuri Kasi Annapurna Devi and Norashidah Md. Din, "Optimization of the Voltage Doubler Stages in an RF-DC Convertor Module for Energy Harvesting,"SciRes, Malaysia, 4 April 2012, hal-219

[5] E.R. Escobar, N.J. Kirsch, G. Kontopidis and B. Turner. 5.5 $\mathrm{GHz}$ optically transparent mesh wire microstrip patch antenna. IEEE Electronics Letters. 2015: Vol.51: 1220.

[6] Yu-Hsuan Lin and Huei Wang. A Low Phase and Gain Error Passive Phase Shifter in $90 \mathrm{~nm}$ CMOS for $60 \mathrm{GHz}$ Phase Array System Application. IEEE Electronics Letters. 2016. 978-15090-0698-4/16-2.

[7] Chung-Yi Hsu, Cho-Ying Chuang, Fu-Kang Wang, Tzyy-Sheng Horng, and Lih-Tyng Hwang. Detection of Vital Signs for Multiple Subjects by Using Self-InjectionLocked Radar and Mutually Injection-Locked Beam Scanning Array. IEEE Proceedings. Kaohsiung 804, Taiwan. 2017 : 978-1-5090-6360-4

[8] Irfan Mujahidin, Rudy Yuwono, Ali Mustofa, and Aisah. Rectifier Using UFO Microstrip Antenna asElectromagnetic Energy Harvester. American Scientific Publishers. 2015. Adv. Sci. Lett. Vol. 21 : 3439-3443.

[9] Irfan Mujahidin, Rudy Yuwono. Rectifier Using UWB Microstrip Antenna as Electromagnetic Energy Harvester for GSM, CCTV and Wifi Transmitter. Journal Of Telecommunications And Information Technology. 2017. Letter.

[10] Liao, S. Circuit and analysis amplifier design, Prentice-Hall International. Englewood Clifs NJ. 1987. pp: 100.

[11] T. Hirota, A. Minakawa, and M. Muraguchi. Reduced-Size Branch-Line and Rat-Race Hybrid for Uniplanar MMIC's. IEEE Trans. Microwave Theory Tech. 1990. vol. MTT-38, pp. 273, March.

[12] Irfan Mujahidin, Sholeh Hadi Pramono, Aziz Muslim. 5.5 Ghz Directional Antenna with 90 Degree Phase Difference Output. Electrical Power, Electronics, Communications, Controls and Informatics Seminar. 2018; Letter.

[13] Tan-Hsiung Ho and Shyh-Jong Chung. Design and Measurement of a Doppler Radar With New Quadrature Hybrid Mixer for Vehicle Applications. IEEE Transactions On Microwave Theory And Techniques. January 2010; Vol. 58, No.

[14] Ashikur Rahman, Victor M. Lubecke, Olga Boric-Lubecke, Jan H. Prins, and Takuya Sakamoto. Doppler Radar Techniques for Accurate Respiration Characterization and Subject Identification. IEEE Journal on Emerging and Selected Topics in Circuits and Systems. June 2018; Volume: 8 , Issue: 2.

[15] Yu-Hsuan Lin and Huei Wang. A Low Phase and Gain Error Passive Phase Shifter in $90 \mathrm{~nm}$ CMOS for $60 \mathrm{GHz}$ Phase Array System Application. IEEE Electronics Letters. 2016; 978-15090-0698-4/16-6.

[16] Liao, S. Circuit and analysis amplifier design, Prentice-Hall International. Englewood Clifs NJ. 1987. pp: 140.

[17] T. Hirota, A. Minakawa, and M. Muraguchi. Reduced-Size Branch-Line and Rat-Race Hybrid for Uniplanar MMIC's. IEEE Trans. Microwave Theory Tech. 1990; vol. MTT-38, pp.275, March.

[18] Nakar, Punit S.Design of a Compact Microstrip Patch Antena for use in Nirkabel/Cellular Devices. Thesis. The Florida State University, 2004: pp : 19,40.

[19] Edgar Hund. Microwave Communications: Components and Circuits. ISE Editions. McGraw-Hill Education. 1989: pp : 43

[20] Marc E. Goldfarb and Robert A. Pucel, "Modeling Via Hole Grounds in Microstrip", IEEE Microwave and Gided Wave Letters. June 1991; Vol. 1 No. 6. 
[21] J. Yamasaki, I. Ohta, T. Kawai, and Y. Kokubo. Design of broadband semi-lumped and lumped-element quadrature hybrids. IEEE Microwave Theory and Techniques Society International Microwave Symposium. Long Beach, California,
USA.
2005;
DOI:
$10.1109 /$

MWSYM

[22] Peter. W. Gorham, Power Dividers And Directional Couplers. University of Hawai'i at Manoa handbook. Jeff Kowalski, pp. 6 41. 